\title{
Ventilation Efficiency Of Push-Pull Ventilation Systems In Residential Buildings - CFD Simulation And Validation Of The Model With Measurements In A Research Apartment
}

\author{
Markus Wirnsberger ${ }^{1}$, Frank Buttinger ${ }^{1}$, Harald Krause ${ }^{1}$ \\ Technical University of Applied Sciences Rosenheim ${ }^{1}$
}

\begin{abstract}
In the project, domestic ventilation concepts with PushPull-Fans were investigated. These ventilation units are characterized by a periodically changing supply and exhaust air operation. To ensure balanced operation, these ventilation units are always used in pairs, with one unit being in the exhaust air mode and the other in supply air mode. Measurements were made in a research apartment. The results were used to validate a CFD simulation model for transient studies. A room-by-room layout with two units in one room and a cross-room ventilation layout with two connected units in two rooms were analysed. The age of air was used as the evaluation parameter. With the room-by-room ventilation layout a lower age of air in the bedroom compared to the cross-room layout was obtained. However, in the room-by-room layout, the air flow through the larger living room with connected corridor was poorer in the rear area. With the cross-room layout, the flow through the rooms was more uniform. With the cross-room layout, the average age of air in the apartment could be slightly reduced compared to the room-by-room layout.
\end{abstract}

\section{Introduction}

In order to comply with the climate change targets, the building stock in Germany must become almost $\mathrm{CO}_{2}$ neutral by 2050 (Bundesministerium für Umwelt, Naturschutz, Bau und Reaktorsicherheit (BMUB), 2016). Private households are responsible for $28 \%$ of energy consumption in Germany, $80 \%$ of which is used for space heating (AGEB, A. E. e.V.G., 2019). In modern, highly insulated buildings, ventilation heat losses contribute up to $50 \%$ of total heat losses. These losses can be significantly reduced by using controlled ventilation with heat recovery. For current ventilation systems, heat recovery rates of $>80 \%$ are usual. Nevertheless, residential ventilation systems are seldom cost-effective, even in new buildings. In addition, $96 \%$ of the energy consumption for residential buildings is required by buildings built before 2001 (Deutsche Energie-Agentur, 2016). This implies that building refurbishment is a critical factor for the success of stopping climate change. The central ventilation systems established on the market are rarely suitable for refurbishment, as the required pipes are usually difficult to install. For these reasons, many building owners decide against controlled dwelling ventilation. The aim is therefore to develop simple ventilation concepts that are suitable for refurbishment and still inexpensive.
PushPull-Fans have been pushing their way onto the market for several years and represent a simple alternative to central ventilation systems. Despite their simple design, PushPull-Fans allow controlled ventilation of domestic houses. The market share of decentralised ventilation units, which also include PushPull-Fans, is steadily increasing (2016 30\% (Interconnection Consulting, 2018)). However, few research projects have been made on this ventilation system. In this study a CFD simulation model was created and validated with measurement data to build the basis for further investigations. The difference between room-wise and room-overlapping coupling of the ventilation units was investigated.

\section{Methods}

\section{Experiments}

In the first step experiments were performed. The results were used in a further step to validate the simulation model. A research apartment with a floor area of $70 \mathrm{~m}^{2}$ was built especially for the investigation of ventilation concepts. The apartment is located in a hall and is thus protected from environmental influences. At the moment the dwelling is subdivided into bedroom, living room, bath and kitchen, which are connected by a corridor. The bedroom has the dimensions $3 \times 5.8 \times 2.8 \mathrm{~m}\left(\mathrm{w}^{*} 1 * \mathrm{~h}\right)$. The living room measures $4 \times 5 \times 2.8 \mathrm{~m}\left(\mathrm{w}^{*} \mathrm{l}^{*} \mathrm{~h}\right)$. The living room is not separated from the corridor by a wall, so the air can circulate freely. The corridor serves as an overflow zone and measures $5 \times 1.9 \times 2.8 \mathrm{~m}\left(\mathrm{w}^{*} 1^{*} \mathrm{~h}\right)$. The bathroom and kitchen were not used for the investigations and were separated airtight from the rest of the apartment. Beneath the bedroom door there is a door gap with a height of 50 $\mathrm{mm}$ and a length of $1.5 \mathrm{~m}$. This gap acts as an overflow opening and connects the bedroom and the living room. Two PushPull-Fans were installed at a height of $1.7 \mathrm{~m}$ in each the living room and the bedroom. The presence of one person in each room was represented by a cylindrical dummy with light bulbs in it. The dummies have a diameter of $0.42 \mathrm{~m}$ and a height of $1.25 \mathrm{~m}$. Each of the dummies have a heat output of $100 \mathrm{~W}$. Figure 1 shows the layout of the apartment and the position of the PushPullFans in the bedroom and living room. The position of the measuring points is also shown. 


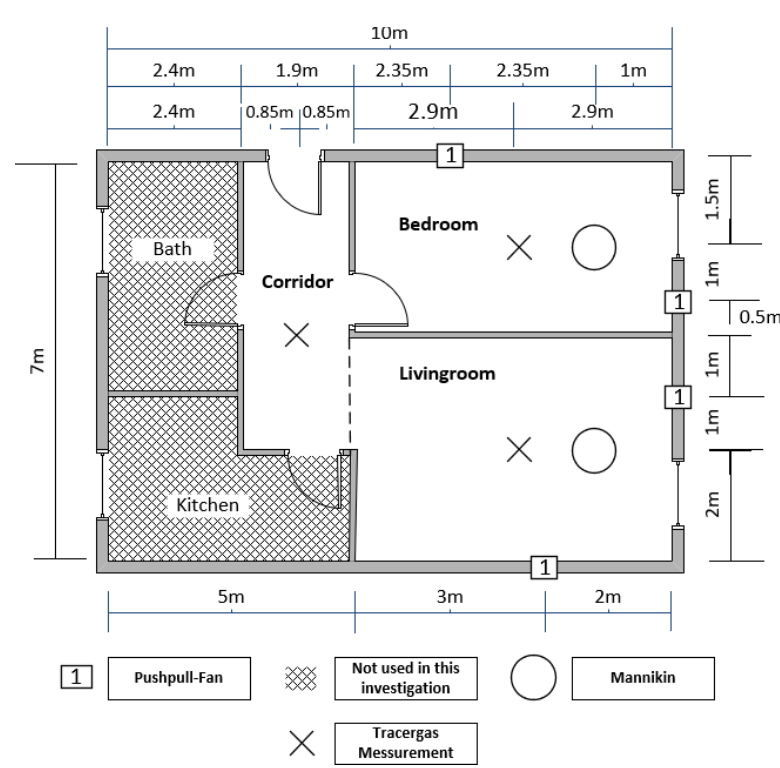

Figure 1 Layout of the research apartment

PushPull-Fans have regenerative heat recovery. The units have a fan that can change the flow direction. In the middle there is a heat accumulator made of either ceramic or aluminium (see Figure 2). Depending on the flow direction, this serves as a heat source or heat sink.

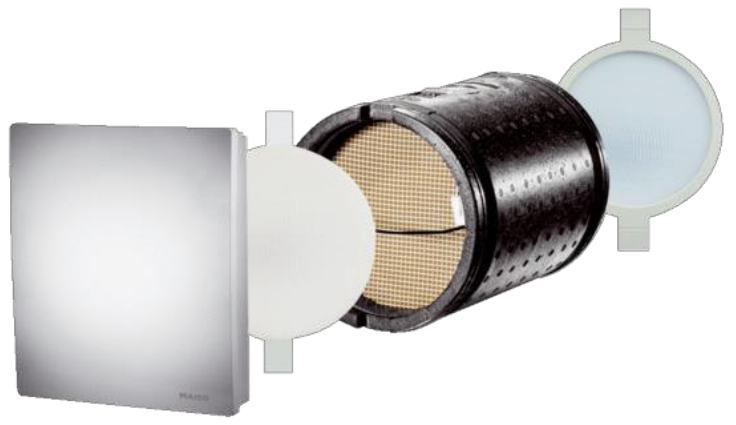

Figure 2 PuspPull-Fan PP60 from Maico (Maico Elektroapparate-Fabrik GmbH, 2019)

The direction of flow is changed after $70 \mathrm{~s}$ intervals. This interval is specified by the manufacturer of the PushPullFan which was used and is the same for other models. It seems to be a compromise between heat recovery and thermal comfort. Each change of direction results in a pause of $10 \mathrm{~s}$ in which no air is moved. In order to prevent a pressure difference between inside the house and outside, the supply and exhaust air volume flowing into the housing unit must be the equal at all times. This is achieved by using an even number of ventilation units. A pressure difference leads to undesired leakage flows and thus to a reduction in the degree of heat recovery. Two ventilation units always form a pair which are coupled together. While one unit is in supply mode, the second unit is extracting the air from the room. After $70 \mathrm{~s}$ the devices change the roles. If there is an air-permeable connection between two rooms, e.g. a door gap, these can also be ventilated with one pair of ventilators.

The PP60 ventilation unit from Maico with a diameter of $200 \mathrm{~mm}$ was used as the PushPull-Fans. This model is

distributed in the same or a similar model by other companies. The opening of the ventilation unit is on the upper side and has a size of $4 \mathrm{~cm} \times 18 \mathrm{~cm}$. The maximum volume flow that the unit can handle in one direction is 45 $\mathrm{m}^{3} / \mathrm{h}$. Since the air handling unit delivers air in one direction for only the half of an hour, a second unit is required to achieve the specified outdoor air flow rate of $45 \mathrm{~m}^{3} / \mathrm{h}$. The maximum air flow rate is $45 \mathrm{~m}^{3} / \mathrm{h}$.

The exhaust air of the PushPull-Fans is blown into the surrounding hall. In order to prevent the exhaust air from being re-circulated, special fresh air hoods (see Figure 3) have been developed. These blow fresh outside air from above onto the PushPull-Fans and push the used air downwards where it leaves into the hall. Additionally, the supply air for decentralised ventilation units and free ventilation can be tempered in this way.

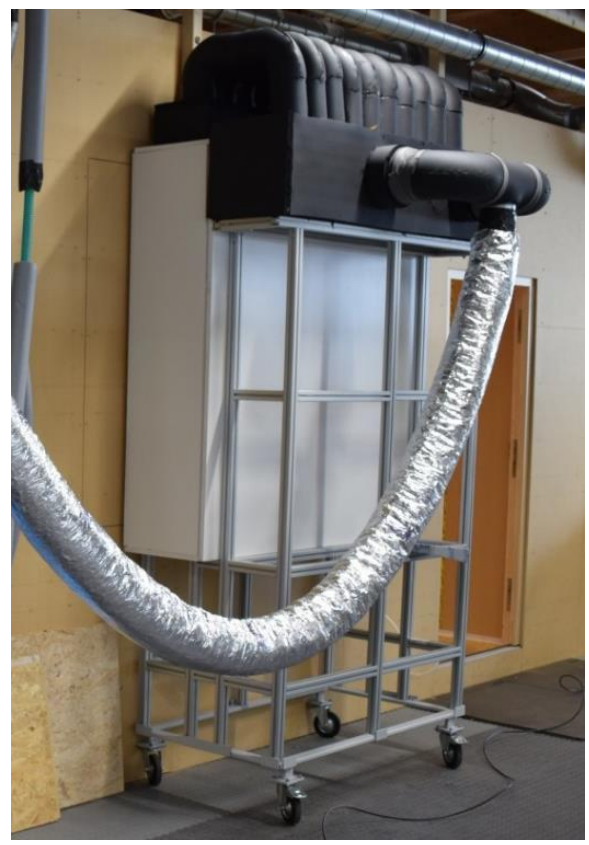

Figure 3 Fresh air hoods for simulating outdoor conditions and providing decentralised ventilation units with tracer gas free air

The necessary volume flows were calculated according to DIN 1946-6:2009 (DIN-Normenausschuss Heiz- und Raumlufttechnik, 2008). Thereafter, the fresh air volume flow for living room and bedroom is $45 \mathrm{~m}^{3} / \mathrm{h}$ each. Two ventilation concepts with different switching times were investigated. In the first case, the two fans in one room were connected. The second case considered the crossroom interconnection of the ventilation units. The outside air temperature during the test was $20{ }^{\circ} \mathrm{C}$. The room temperature at the beginning of each experiment was 20 ${ }^{\circ} \mathrm{C}$.

The air exchange rate was determined using the tracer gas $\mathrm{SF}_{6}$. For this the decay method was used. This means that gas was injected into the apartment and homogeneously distributed with fans until the start concentration was reached. The decay of the gas concentration was then measured in the rooms at a height of $1.1 \mathrm{~m}$ (see Figure 1) and in the ventilation units with the photoacoustic gas monitor INNOVA 1512 (Normenausschus Bauwesen, 2013). 


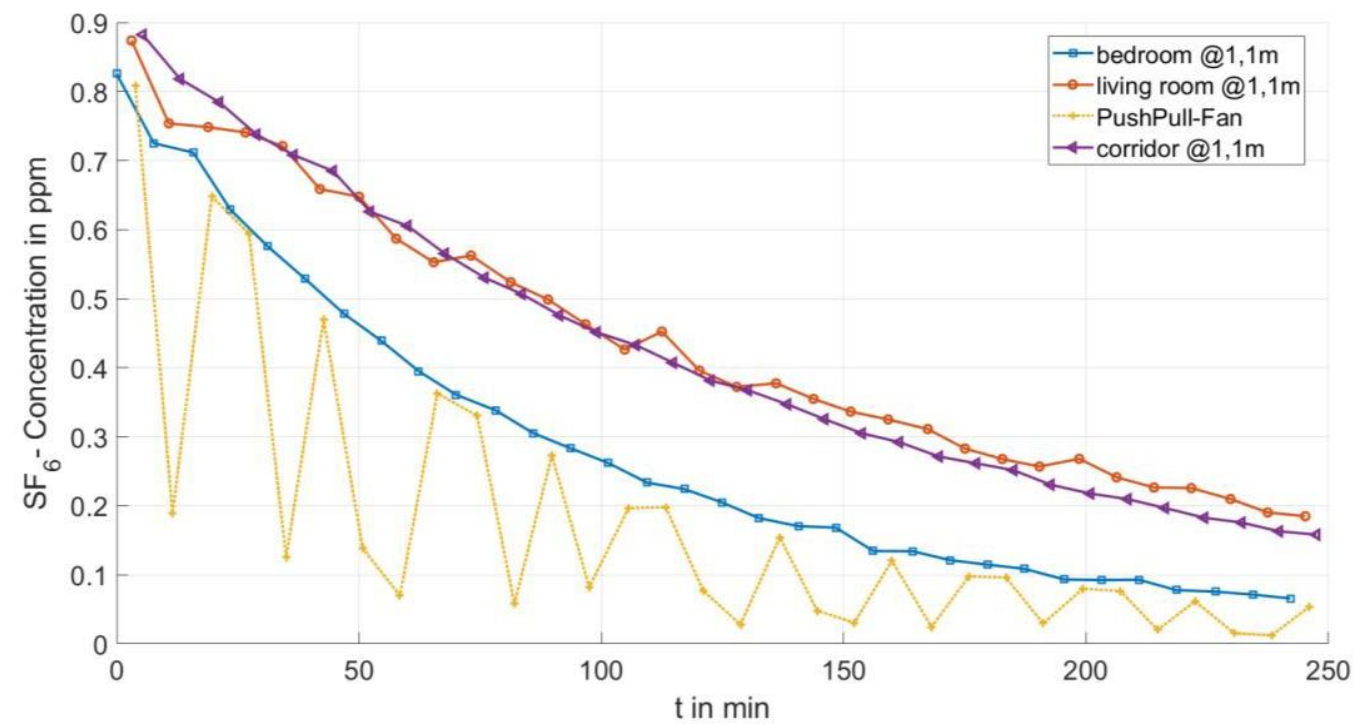

Figure 4 SF6 concentration measured in the research apartment during a room-by-room ventilation with a switching time of 70 s

Figure 4 shows the $\mathrm{SF}_{6}$ concentration for the room-byroom layout in which the two ventilation units in the same room are coupled as a pair. The INNOVA 1512 is not able to analyse different samples simultaneously. This leads to fluctuating values in the ventilators, because the sample was either taken in supply or exhaust air mode. If a concentration close to the room concentration is measured, the unit is in the exhaust phase. At a low $\mathrm{SF}_{6}$ concentration, the air is blown into the room. During the measurements, an $\mathrm{SF}_{6}$ concentration of $15 \%$ of the concentration in the room was found in the supply air.

\section{$\underline{\text { Simulation }}$}

\section{Geometry}

The CFD simulation was performed with ANSYS 19.0 CFX. The research apartment could be reproduced in a simulation model with high closeness to reality. (see. Figure 5).

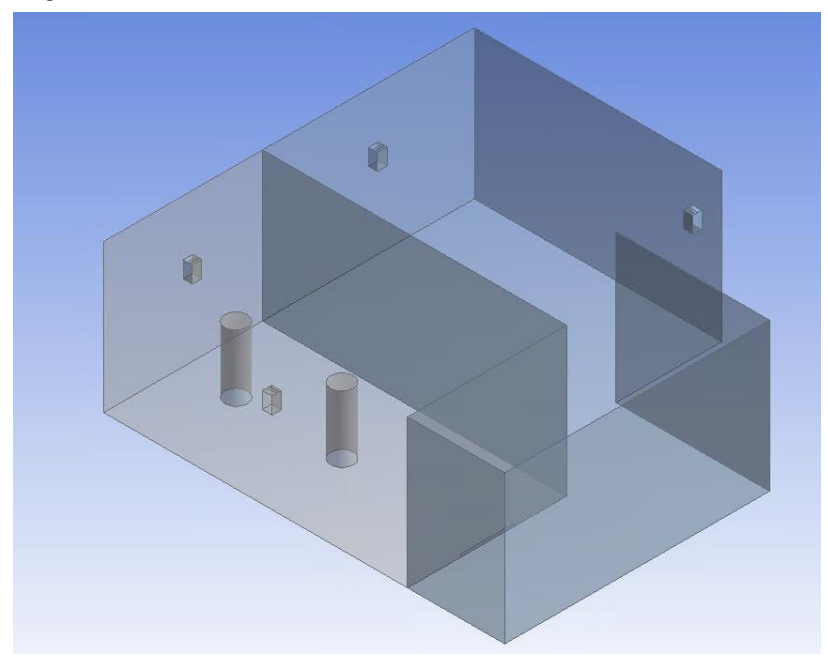

Figure 5 Geometry of the research apartment used for the simulation

The ventilation units were represented as cuboids. Separate openings were created for the inlet and outlet to define those specific boundary conditions (see Figure 6). The dummies for the heat dissipation were also modelled.

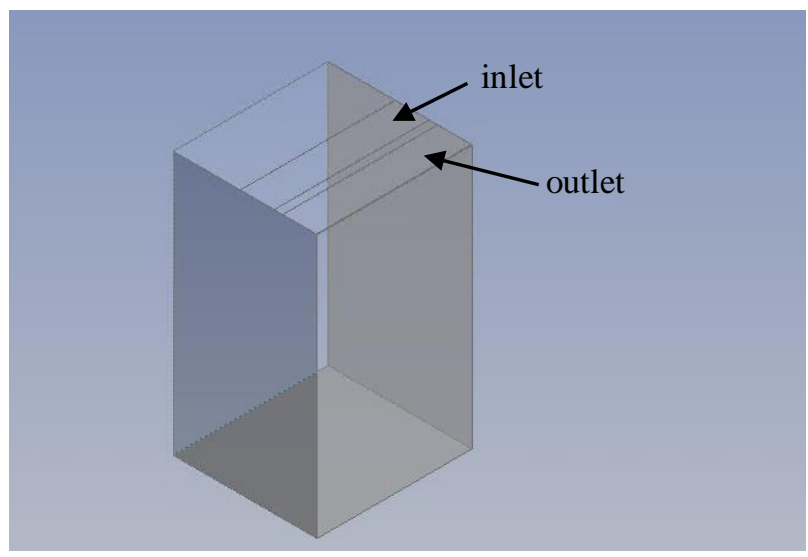

Figure 6 Simplified geometry of the PushPull-fan with separated inlet and outlet

$\underline{\text { Mesh }}$

The mesh consists of 745,000 tetrahedral cells.. For inflation, the height of the first node was set at $5 \mathrm{~mm}$. Due to the small temperature differences the influence of the wall areas is negligible. The boundary layer is therefore not fully dissolved. The height of the first node in the inflation zone was set to $5 \mathrm{~mm}$. The element size for the door gap and for the air in- and outlets is $10 \mathrm{~mm}$. On the outer hull and the surface of the dummies, the element size has been set to $100 \mathrm{~mm}$. 


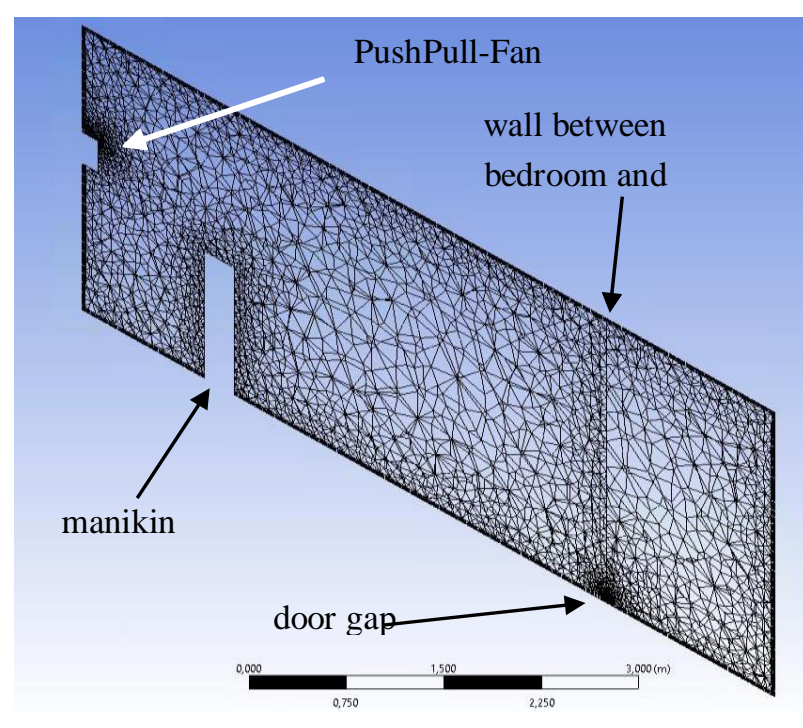

Figure 7 Cut through the mesh of the bedroom and the corridor

\section{Boundary conditions}

The bedroom and the living room incl. corridor were created as two separate domains. The two domains are connected by the door gap as an interface.

The boundary conditions of the ventilation units were defined as mass flow condition, a volume flow of $45 \mathrm{~m}^{3} / \mathrm{h}$ multiplied with the density of air was used. The air was blown into the room by a device for $60 \mathrm{~s}$ and at the same time extracted from the room by the partner device. A break of $10 \mathrm{~s}$ abates the flow before the ventilation devices change the air direction. A fixed temperature of $20^{\circ} \mathrm{C}$ was set for the air inlet and for the outside wall temperature.

The $\mathrm{k}-\varepsilon$ turbulence model was used, as this model simulates turbulence in a more realistic way than theSST turbulence model when simulating room air flows (Lu \& Vilijanen, 2011).

For the determination of the age of air an additional variable was used, for which a further transport equation is solved. The age of air moves in the same manner as the air in the room. The kinematic diffusivity is therefore 0 $\mathrm{m}^{2} / \mathrm{s}$. To reproduce the leakage of the tracer gas in the supply air (s. Figure 4), the value of the age of air in the supply air was set to $15 \%$ of the mean room age of the air (see eq. 1).

$$
\text { AgeofAir }_{\text {Inlet }}=\text { AgeofAir } \text { room }_{\text {mean }} * 0.15
$$

The heat output of the dummies was set as heat flow for the cylindrical surface and the top of the cylinder.

\section{Results}

A validation of the simulation model by the comparison of air velocity is opposed by the strong temporal and spatial variation of such. The use of differential pressures for the validation is difficult because the differential pressures in residential ventitation are very low. E.g.

Rome, Italy, Sept. 2-4, 2019 permissible differential pressure for overflow elements 1.5 Pa. (DIN-Normenausschuss Heiz- und Raumlufttechnik, 2008). Therefore, the air age was used for the validation. This makes it possible to compare transient boundary conditions over a longer period of time. If the air age matches between simulation and measurements, the average air velocities and differential pressures are

also the same. The nominal time constant $\tau_{n}$ (see eq. 2) describes how long it takes until the air has been replaced in a room with an ideal air flow. $\tau_{n}$ is calculated from the volume of the room $V_{\text {room }}$ and the volume flow $\dot{V}_{\text {exchange }}$ which is equal to the outdoor air volume flow. This is also equal to the reciprocal air exchange rate $\beta$.

$$
\tau_{n}=\frac{1}{\beta}=\frac{V_{\text {room }}}{\dot{V}_{\text {exchange }}}
$$

For the bedroom with a volume of $40 \mathrm{~m}^{3}$, the exchange volume flow of $45 \mathrm{~m}^{3} / \mathrm{h}$ results in a $\tau_{n}$ of $0.9 \mathrm{~h}$. The bedroom and the corridor together have a volume of 83 $\mathrm{m}^{3}$. With the same volume flow as in the bedroom, a $\tau_{n}$ of $1.8 \mathrm{~h}$ is calculated.

The simulation was continued until the age of air in the apartment has reached a stationary level. Figure 8 shows the distribution of the air age of the apartment for the room-by-room layout at a height of $1.1 \mathrm{~m}$ for a changeover time of $70 \mathrm{~s}$. In the bedroom the age of air ranges from $1.5 \mathrm{~h}$ to $1.8 \mathrm{~h}$. The age of the air in the living room and in the corridor reaches values between $1.8 \mathrm{~h}$ $3.1 \mathrm{~h}$.

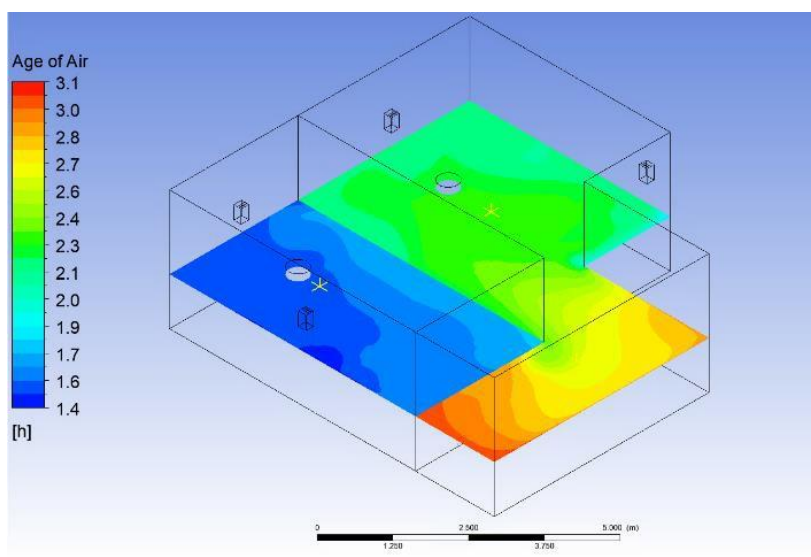

Figure 8 Age of air for room-by-room ventilation with a switching time of $70 \mathrm{~s}$ at a high of $1.1 \mathrm{~m}$

Figure 9 shows the distribution of the age of air in the apartment at a height of $1.1 \mathrm{~m}$ for the cross-room ventilation layout and a switching time of $70 \mathrm{~s}$. In the bedroom the age of air reaches values between $1.6 \mathrm{~h}-2.1$ $\mathrm{h}$. For the living room and the corridor, the values are 2.0 $\mathrm{h}-2.5 \mathrm{~h}$. 


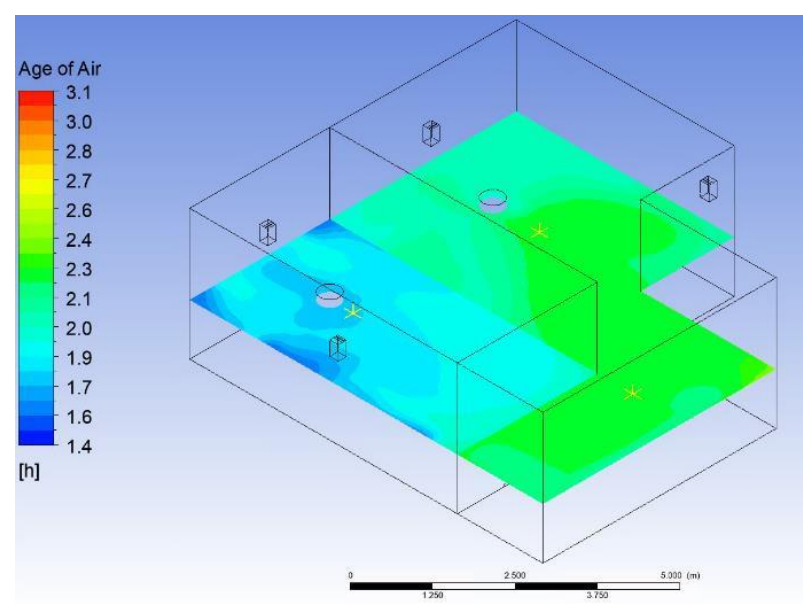

Figure 9 Age of air for cross-room ventilation with a switching time of $70 \mathrm{~s}$ at a high of $1.1 \mathrm{~m}$

The results for the measured samples in the bedroom, living room and corridor from the experiments and the measurements are shown in Figure 10. The agreement between experiment and simulation confirms the validity of the simulation model. The results show that a uniform average age of air of around 2 hours is achieved in all rooms with cross-room ventilation. With room-by-room ventilation, the mean age of air in the bedroom decreases to 1.6 hours. In the bedroom, the mean air age increases to $2.3 \mathrm{~h}$. In the corridor there is also an increase to $2.7 \mathrm{~h}$.

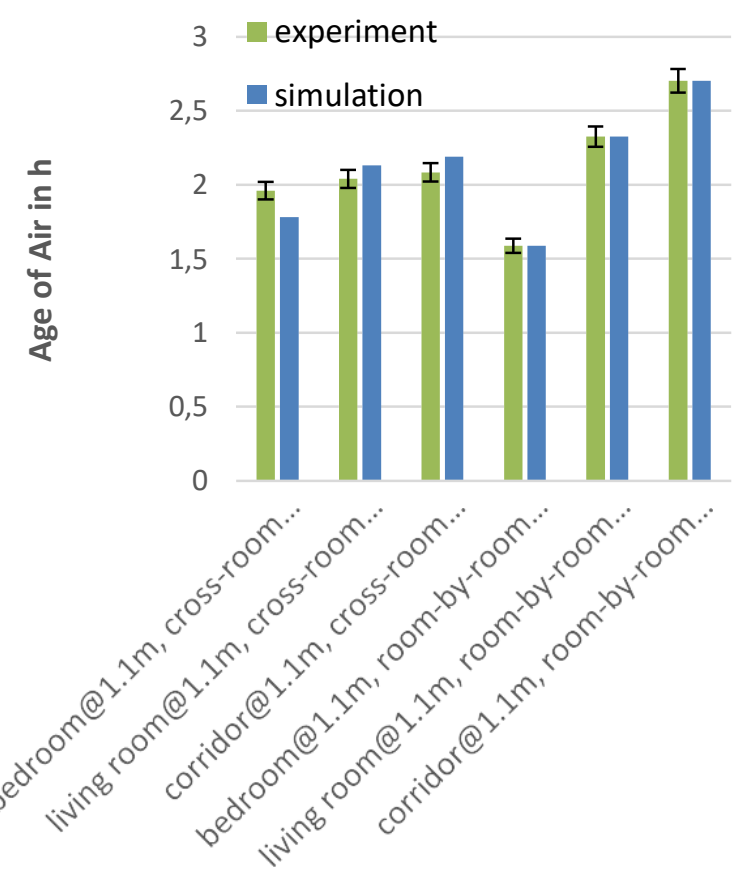

Figure 10 Results of the experiments and measurements of the room-by-room and cross-room ventilation layout for a switching time of $70 \mathrm{~s}$

The air exchange efficiency $\varepsilon^{a}$ describes the flow pattern in a room. With an air exchange efficiency of 1 it is a piston flow, with an air exchange efficiency of 0.5 it is a perfect mixed flow. If the air exchange efficiency is less than 0.5 , the flow tends to a short circuit. The air exchange efficiency is calculated from the nominal time constant $\tau_{n}$ and the mean age of air $\dot{\tau}_{a}$ (see eq. 3 ). With a better air exchange rate, less air is needed to achieve the same air quality.

$$
\varepsilon^{a}=\frac{\tau_{n}}{2 * \dot{\tau}_{a}}
$$

For the cross-room ventilation layout, the average age of the air in the bedroom is $1.8 \mathrm{~h}$. The air exchange efficiency is therefore 0.25 . The mean age of the air in the living room and the corridor is $2.2 \mathrm{~h}$, resulting in an air exchange efficiency of 0.4 . For the layout with room-by-room ventilation the bedroom has an average age of air of $1.6 \mathrm{~h}$ and an air exchange efficiency of 0.28 . For the living room and the corridor, the room-by-room ventilation layout results in a mean age of air of $2.4 \mathrm{~h}$ and thus an air exchange efficiency of 0.38 . All air exchange efficiencies are less than 0.5 . All ventilation layouts are therefore not as effective as mixed ventilation.

With the local air age measured at one point $\tau_{a_{p}}$ the local air exchange efficiency $\varepsilon_{p}^{a}$ can be determined. Figure 11 shows the local air exchange efficiencies for cross-room and room-by-room ventilation determined in the simulation at the measurement points in the bedroom, living room and corridor. The lowest local air exchange efficiency was achieved in the bedroom with 0.25 with cross-room ventilation. With room-by-room ventilation, the local air exchange efficiency in the bedroom was

slightly better with 0.28 . In the living room, a local air exchange efficiency of 0.39 was achieved with room-byroom ventilation and could be increased to 0.42 with cross-room ventilation. In the hallway, room-by-room ventilation resulted in an air exchange efficiency of 0.33 and increased to a value of 0.41 for cross-room ventilation.

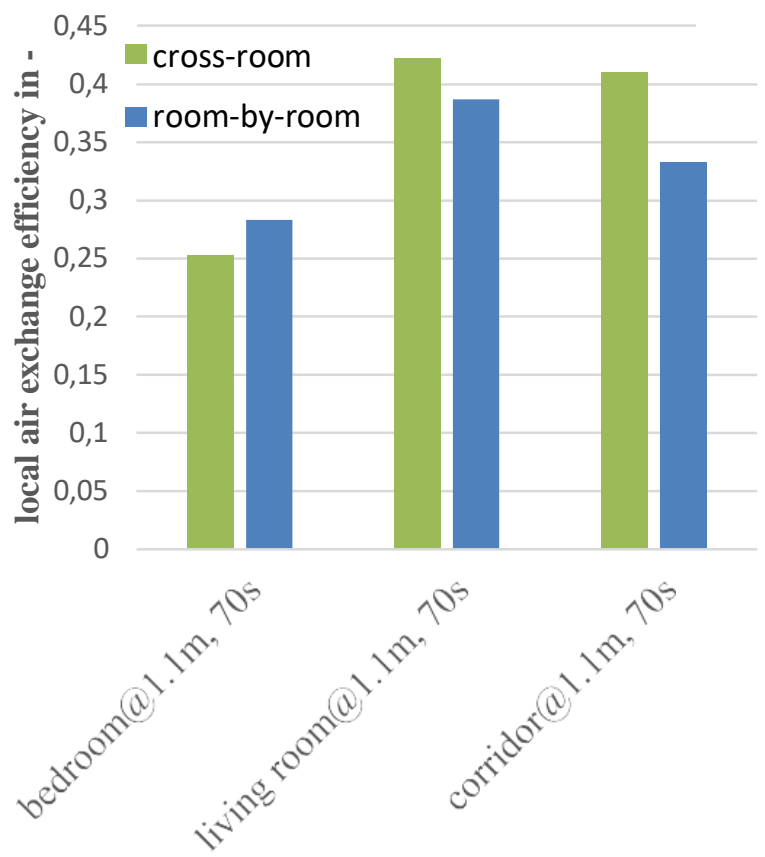

Figure 11 Local air exchange efficiencies of the simulation at the measurement points in the bedroom, living room and the corridor for cross-room ventilation and room-by-room ventilation 


\section{Conclusion}

With the room-by-room ventilation layout, the differences in the age of the air between the rooms are larger. In this case, the bedroom has a smaller air age as the other rooms. In the cross-room ventilation layout, the age of the air of the rooms adapts to a uniform level. Compared to roomby-room ventilation, the age of air in the living room and the corridor is lower with cross-room ventilation. From this it can be deduced that the room air flow in large rooms can be improved by cross-room ventilation. If the complete apartment is considered, an average age of air of $2.2 \mathrm{~h}$ and an average air exchange efficiency of 0.33 result for the room-by-room ventilation layout. For the crossroom ventilation, an average age of air of $2.0 \mathrm{~h}$ and an average air exchange efficiency of 0.36 result. Regarding the whole apartment, a cross-room ventilation concept provides better ventilation.

Like all decentralised ventilation units, PushPull-Fans naturally have the option of adapting the air flow for each room to the requirements. In addition, the ventilation units could be interconnected as desired. The only limitation is the condition that the supply and exhaust air volume flows of the apartment must be balanced at all times to achieve a maximum level of heat recovery. In ventilation concepts with PushPull-Fans not only the amount of air can be adjusted to the demand, but also the air routing. During the day, for example, a cross-room ventilation concept could be used to ensure good air quality throughout the dwelling. At night, a room-by-room ventilation concept is used to improve the air quality in the bedroom. The design of such new concepts will be addressed in a forthcoming project.

\section{References}

AGEB, A. E. e.V.G. (2019). Anwendungsbilanzen für die Endenergiesektoren in Deutschland in den Jahren 2013 bis 2017. Retrieved from www.ag-energiebilanzen.de

Bundesministerium für Umwelt, Naturschutz, Bau und Reaktorsicherheit (BMUB). (2016). Klimaschutzplan 2050. Retrieved from www.bmub.bund.de

Deutsche Energie-Agentur . (2016). Statistiken und Analysen zur Energieeffizienz im Gebäudebestand.

DIN-Normenausschuss Heiz- und Raumlufttechnik. (2008). Ventilation and air conditioning Part 6: Ventilation for residential buildings General requirements, requirements for design, construction, commissioning and handover as well as maintenance (DIN19466:2009-05).

Interconnection Consulting. (2018). Kontrollierte Wohnraumlüftung in Europa.

Lu, X., \& Vilijanen, M. (2011). A novel and dynamix demand-controlled ventilation strategy for $\mathrm{CO} 2$ control and energy saving in buildings. Energy and Buildings 43, S. 2499-2508.
Normenausschus Bauwesen. (2013).

Wärmetechnisches Verhalten von Gebäuden und Werkstoffen-Bestimmung des spezifischen Luftvolumenstrom in Gebäuden Indikatorgasverfahren (DIN EN ISO 12569:2013-03).

12569:2013-03).

